\title{
Genome-wide Association Study of Strawberry Fruit Quality-related Traits Using a MAGIC Population Derived from Crosses Involving Six Strawberry Cultivars
}

\author{
Takuya Wada ${ }^{1 *}$, Masao Tsubone ${ }^{1}$, Miyuki Mori', Chiharu Hirata ${ }^{1}$, Shiro Nagamatsu ${ }^{1}$, \\ Koichiro Oku1, Soichiro Nagano², Sachiko Isobe ${ }^{2}$, Hideyuki Suzuki ${ }^{2,3}$, Katsumi Shimomura1, \\ Noriko Baba $^{4}$, Keita Hirashima ${ }^{1}$, Takayuki Sueyoshi', Ko-ichi Obu', Hidetoshi Ikegami', \\ Yosuke Uchimura ${ }^{1}$ and Tatsuya Hayashida ${ }^{1}$
}

\author{
${ }^{1}$ Fukuoka Agricultural and Forestry Research Center, Chikushino 818-8549, Japan \\ ${ }^{2}$ Department of Frontier Research and Development, Kazusa DNA Research Institute, Kisarazu 292-0818, Japan \\ ${ }^{3}$ Department of Applied Genomics, Kazusa DNA Research Institute, Kisarazu 292-0818, Japan \\ ${ }^{4}$ Institute of Agricultural and Forest Resources, Fukuoka Agricultural and Forestry Research Center, Kurume 839-1212, Japan
}

\begin{abstract}
Cultivated strawberry is one of the important commercial fruits not only in Japan, but around the world. Even so, analyzing regions responsible for fruit quality traits of cultivated strawberry has been very challenging due to the alloploidy and octoploidy of genome conformation. In order to solve this problem, we previously developed a strawberry multi-parent advanced generation inter-cross (MAGIC) population derived from crosses involving six cultivars. Here, we performed genotyping of the MAGIC population with simple sequence repeat (SSR) markers, which were generated from an expressed sequence tag site, and conducted a genomewide association study of $\mathbf{1 3}$ strawberry fruit quality-related traits to reveal associated quantitative trait loci (QTLs). Correlation coefficients among fruit color-related traits, such as fruit surface color (FSC), fruit surface anthocyanin content (FSA), and fruit flesh anthocyanin content (FFA) were relatively higher, but FSC, FSA, and FFA did not show any higher correlation with other traits. Fruit weight (FW), FSC, and fruit firmness, including whole fruit firmness (WFF), fruit surface firmness (FSF), and fruit flesh firmness (FFF), indicated higher year to year correlation coefficients than other fruit quality-related traits. Among FW, FSC, and WFF, there were only two QTLs for FW, five for FSC, and 38 for WFF (the most) and they were detected on all chromosomes. QTLs for some traits shared common flanking simple sequence repeat markers, and allelic differences of one marker affected the variation of other traits. QTLs for fruit firmness were most frequently detected, followed by those for SSC and titratable acidity (TA). Allelic differences in these QTLs negatively affected FSC, the fruit surface anthocyanin content (FSA), and fruit flesh anthocyanin content (FFA), implying that alleles which increase fruit firmness, SSC, and TA lighten fruit color. Similarly, QTLs for FSC, FSA, and FFA mostly negatively affected FSF, FFF, SSC, and TA and did not affect WFF. This indicated that simultaneous improvement in fruit firmness, SSC, and TA is possible with many markers, but improving fruit firmness and deepening fruit color are highly challenging.
\end{abstract}

Key Words: allelic effect, anthocyanin, fruit color, fruit firmness, QTL.

Received; January 13, 2020. Accepted; April 27, 2020

First Published Online in J-STAGE on June 27, 2020.

This study was partly supported by JSPS KAKENHI (Grant Number 18K05639), the Genomics for Agricultural Innovation (DHR1 to S.I.), and the Science and Technology Research Promotion Program for agriculture, forestry, fisheries, and food industry (27003A to S.I.) of the Ministry of Agriculture, Forestry, and Fisheries of Japan.

No conflicts of interest declared.

* Corresponding author (E-mail: tawada@farc.pref.fukuoka.jp).

\section{Introduction}

Cultivated strawberry (Fragaria $\times$ ananassa Duch.) is an important fruit species both in Japan and worldwide. This alloploid species has a highly heterozygous octoploid genome $(2 n=8 x=56)$ (Darrow, 1966), and genome structure; the $\mathrm{AAA}^{\prime} \mathrm{A}^{\prime} \mathrm{BBB}^{\prime} \mathrm{B}^{\prime}$ model, proposed by Bringhurst (1990) has been supported until recently, and disomic inheritance of cultivated strawberry was 
also validated by recent molecular approaches (Kunihisa et al., 2005; Rousseau-Gueutin et al., 2008; Honjo et al., 2013; Isobe et al., 2013). Furthermore, Edger et al. (2019) conducted a comprehensive analysis of genome structure using new generation sequencing technology and revealed that cultivated strawberry originated from four distinct ancestors, F. vesca, F. iinumae, F. nipponica, and F. viridis. Complexities in the cultivated strawberry genome have prevented researchers from detecting quantitative trait loci (QTLs) for important agronomic traits and developing DNA markers closely linked to these traits (Husaini and Neri, 2016).

Before the $F . \times$ ananassa genome was analyzed, Shulaev et al. (2011) sequenced the genome of a wild diploid relative of cultivated strawberry, Fragaria vesca 'Hawaii 4'. Additionally, microsatellite linkage maps were independently developed (Sargent et al., 2012; Isobe et al., 2013). Furthermore, Hirakawa et al. (2014) revealed the $F . \times$ ananassa subgenomic structure in a comparison with other Fragaria species. Bassil et al. (2015) developed a 90K single nucleotide polymorphism (SNP) array for high-throughput genotyping of cultivated strawberry and using this array, Sargent et al. (2016) constructed a linkage map for cultivated strawberry. Recently, Edger et al. (2019) performed chromosome-scale assembly and annotation of the 'Camarosa' cultivar genome, revealing that the total genome length was around 805 million bp and that cultivated strawberry was derived from four different wild strawberries. These previous genome sequence and marker studies generated useful information regarding wild strawberry genetics, with implications for the breeding of cultivated strawberry.

The above-mentioned genome resources, combined with phenotype information, provide considerable information about the genetic regions controlling strawberry fruit quality-related traits. Zorrilla-Fontanesi et al. (2011) completed a QTL analysis of 17 agronomic and fruit quality-related traits using an $F_{1}$ population derived from an intra-specific cross between two contrasting selection lines, '232' and '1392', and detected 33 QTLs for 14 traits. Lerceteau-Köhler et al. (2012) identified many QTLs for 19 fruit-related traits using 213 full-sibling $F_{1}$ progenies from a cross between the variety 'Capitola' and the genotype 'CF1116'. Castro and Lewers (2016) developed an $F_{1}$ population derived from the 'Delmarvel' $\times$ 'Selva' cross, and mapped several QTLs for fruit quality-related traits and flowering time. These QTLs are useful for the marker-assisted breeding of cultivated strawberry. However, the effectiveness of QTLs detected using populations from biparental crosses is limited because these QTLs reflect the genetic variation between the relevant parent lines, so the application of QTLs should be further evaluated. A genome-wide association study (GWAS) can address this issue. A GWAS is usually completed with general varieties or a population derived from a multi-parent advanced generation inter-cross (MAGIC) to cover wider genetic variation than that of a bi-parental cross. A GWAS requires more DNA markers than a conventional QTL analysis because a low DNA marker density may lead to the detection of false- positive QTLs. However, recent advances in the analysis of plant genomes has enabled the development of DNA markers for highresolution genomic studies. In the family Rosaceae, apple and peach have been frequently analyzed using GWAS (Micheletti et al., 2015; Cao et al., 2016; Kunihisa et al., 2016; Urrestarazu et al., 2017). In strawberry, Gezan et al. (2017) validated the effectiveness of the genomic selection of cultivated strawberry. Pincot et al. (2018) completed a GWAS of strawberry traits in terms of resistance to Fusarium wilt. However, QTLs for fruit quality-related traits in strawberry have not been reported.

We herein developed a strawberry MAGIC population derived from six founder parental lines ('Fukuoka S6', 'Kaorino', 'Sachinoka', '06A-184', 'Beni hoppe', and 'Ookimi') (Wada et al., 2017). Analysis of this MAGIC population indicated that among six fruit quality-related traits, fruit surface color (FSC) had the highest correlation coefficient between two consecutive years, followed by whole fruit firmness (WFF). These observations implied that genetic factors strongly affect the differences in FSC and WFF among strawberry cultivars.

The objectives of this study were to complete a GWAS of strawberry fruit quality-related traits using a MAGIC population, and to reveal the genetic regions for FSC, WFF, and other fruit quality-related traits, including days to flowering (DTF), fruit weight (FW), fruit surface anthocyanin content (FSA), fruit flesh anthocyanin content (FFA), fruit surface firmness (FSF), fruit flesh firmness (FFF), soluble solids content (SSC), titratable acidity (TA), sucrose content (SC), glucose content (GC), and fructose content (FC).

\section{Materials and Methods}

\section{Plant materials}

The MAGIC population analyzed in this study was derived from the following six strawberry $(F . \times$ ananassa) cultivars: 'Fukuoka S6', 'Kaorino', 'Sachinoka', '06A-184', 'Beni hoppe', and 'Ookimi'. This population comprised second generation intercross $\left(\mathrm{IC}_{2}\right)$ populations, and consisted of 338 individual plants. Details regarding the development of this MAGIC population and its major fruit quality-related traits have been reported previously (Wada et al., 2017). Taking into account population structure, $\mathrm{F}_{1}$ and $\mathrm{IC}_{1}$ plants were selected and crossed by firstly prioritizing rare allele frequencies and secondly the genetic diversity of each simple sequence repeat (SSR) marker according to their heterozygote values (Isobe et al., 2013). 


\section{Genotyping of the MAGIC population}

Genotyping of the MAGIC population was completed using genome-wide expressed sequence tag (EST) and SSR markers (Isobe et al., 2013). We used a set of 336 EST-SSR markers (total allele number: 1,343), which were confirmed to be polymorphic among first generation inter-cross populations. The average marker density was 48 markers per $F$. vesca chromosome. The extraction of genomic DNA, as well as PCR and fragment analyses, were completed as previously described (Wada et al., 2017). Polymorphisms were confirmed using Gene Marker software (Softgenetics LLC, State College, PA, USA) based on the presence $(+)$ or absence (-) of the relevant peak. SSR markers are usually used as co-dominant markers, but cultivated strawberry has an octoploid genome. Therefore, most of the SSR markers in this study generated multiple peaks, and it was almost impossible to detect allelic relationships among all peaks. Furthermore, it was impossible to determine whether a peak corresponded to a single chromosome locus or multiple chromosome loci. Accordingly, all SSR markers were considered to be dominant markers. Taking into account the corresponding locus of homoeologous chromosomes, the lowest minor allele frequency was assumed to be $1 / 48$. As a result, SSR markers with segregation ratios in the MAGIC population of less than 1/48 were excluded from the subsequent GWAS.

\section{Evaluation of MAGIC population traits}

Traits related to fruit quality (Days to flowering (DTF), Fruit weight (FW), Fruit surface color (FSC), Fruit surface anthocyanin (FSA), Fruit flesh anthocyanin (FFA), Whole fruit firmness (WFF), Fruit surface firmness (FSF), Fruit flesh firmness (FFF), Soluble solid content (SSC), Titratable acidity (TA), Sucrose content (SC), Glucose content (GC), and Fructose content (FC)) were evaluated for individual plants from crossed seeds and propagated clones of the MAGIC population from the 2013-2014 season (hereafter designated 2013) to the 2017-2018 season (hereafter designated 2017). The crossed seeds of the $\mathrm{IC}_{2}$ generation were sown on May 27, 2013 in nursery soil for vegetable seeds (Takii \& Co., Ltd., Kyoto, Japan). The resulting plants were transferred to nursery pots $(9 \mathrm{~cm}$ diameter) containing strawberry nursery soil (Seishin Industry, Fukuoka, Japan), and incubated in a nursery. In the other seasons, cloned seedlings derived from the $\mathrm{IC}_{2}$ plants of the 2013 season underwent trait evaluations. All subsequent cultivation was performed in a greenhouse. Transplanting dates and evaluated traits for each year are listed in Table S1. Among the examined traits, DTF, FW, and FSC were evaluated for five years, WFF, FSA, FFA, FSF, FFF, SSC, and TA were evaluated for three years, and SC, GC, and FC were evaluated only in 2013. All experiments were performed with one replication in each year.
Prior to transplantation, basal fertilizer was applied $\left(5: 3.8: 1.9 \mathrm{~g} \cdot \mathrm{m}^{-2} ; \quad \mathrm{N}: \mathrm{P}_{2} \mathrm{O}_{5}: \mathrm{K}_{2} \mathrm{O}\right)$. Additional fertilizer was applied approximately 30 days after transplantation $\left(10: 11.8: 11.3 \mathrm{~g} \cdot \mathrm{m}^{-2} ; \mathrm{N}: \mathrm{P}_{2} \mathrm{O}_{5}: \mathrm{K}_{2} \mathrm{O}\right)$. Plants were watered and weed growth was controlled as necessary. Additionally, plants were not exposed to artificial lighting. Anthesis was considered to have occurred when the first flower bloomed on the primary branch. Fruit quality-related traits were assessed using fruits harvested from the primary branch when plants reached maturity. However, the first fruit on the primary branch was excluded because it tended to develop an abnormal shape due to nutritional imbalance. Therefore, five fruits (second to sixth fruits) from the primary branch were analyzed in term of FW and FPC. Three fruits (second, third, and fourth fruits) were assessed for WFF, FSF, FFF, SSC, TA, SC, GC, and FC, and two fruits (fifth and sixth fruits) were evaluated for FSA and FFA. FW, FSC, WFF, FSF, FFF, SSC, TA, FSA, and FFA were analyzed as previously described (Wada et al., 2017). Because FSC was calculated by $L^{*}$ (lightness) multiplied by $b^{*}$ (blue-yellow color component) and divided by $a^{*}$ (green-red color component), lower FSC values were correlated with a deeper red color. SC, $\mathrm{GC}$, and $\mathrm{FC}$ were determined using $2 \mathrm{~mL}$ strawberry fruit juice that was diluted to $10 \mathrm{~mL}$ with ethanol and stored at $-80^{\circ} \mathrm{C}$ before undergoing high-performance liquid chromatography with a JASCO LC-2000Plus system (JASCO Corporation, Tokyo, Japan) and the following conditions: pump, PU-2080; column, Shodex Asahipak NH2P-50 4E (Showadenko K. K., Tokyo, Japan); column temperature, $40^{\circ} \mathrm{C}$; mobile phase, $75 \%$ acetonitrile; flow rate, $1.0 \mathrm{~mL} \cdot \mathrm{min}^{-1}$; sample injection volume, $20 \mu \mathrm{L}$; detector, RI-2031. The resulting fraction peaks for sucrose, glucose, and fructose were converted to sugar contents with the ChromNAV program (JASCO).

\section{Correlation of fruit quality-related traits}

Inter-year correlation coefficients of 10 fruit qualityrelated traits, except for SC, GC, and FC, were calculated. Furthermore, average trait values throughout the experimental years for the above-mentioned 10 traits were calculated and correlation coefficients among eight traits, DTF, DW, FSC, WFF, FSA, FFA, SSC, and TA, were evaluated in order to evaluate the relationship among fruit quality-related traits.

\section{Genome-wide association study of fruit quality-related} traits

A GWAS of fruit quality-related traits was conducted using the general linear model (GLM) of the TASSEL 5 program $(<$ https://www.maizegenetics.net $>)$. Before the association study, principle component analysis (PCA), which was implemented in TASSEL, was performed to evaluate the population structure of our MAGIC population. Then, GWAS was conducted separately with and 
without correction for population structure, and the two results were compared. Loci for which the $-\log _{10} P$ value exceeded the threshold level of the Bonferroni multiple correction test (i.e., 4.429 and 5.128 at $5 \%$ and $1 \%$ levels, respectively) were selected using average trait values for all experimental years and individual trait values in each year separately. When $-\log _{10} P$ values of the SSR markers were significant in GWAS using average trait values, we assumed that QTLs were present nearby the relevant marker loci. However, because SC, GC, and FC were only analyzed in 2013, the associated QTLs were adopted when the corresponding loci only exceeded the threshold level in 2013. QTLs were named and numbered based on the combination of trait name abbreviations and the order of corresponding marker positions of the Fragaria vesca genome v2.0.a1 (Tennessen et al., 2014). Additionally, we performed cluster analysis using genotype data of the MAGIC population and assumed that multiple markers, which shared approximately the same cluster and showed similar segregation patterns, were common flanking markers of QTLs.

Analyzing allelic effects of significant QTLs for fruit quality-related traits, and selection of candidate SSR markers for marker-assisted breeding of strawberry fruit quality-related traits

To analyze the allelic effects of each significant locus, we divided the MAGIC population into two groups based on the presence $(+)$ or absence $(-)$ of an allele (hereafter designated allele groups) at each locus. Based on the comparison of mean values of each allele group, positive alleles were detected to improve the relevant trait. Candidate SSR markers flanking QTLs for multiple traits were selected for marker assistedbreeding of strawberry fruit quality-related traits. After selection, selection effects were evaluated using the following equation:

$$
\Delta \mathrm{D}=\operatorname{Mean}_{(-)}-\operatorname{Mean}_{(+)}
$$

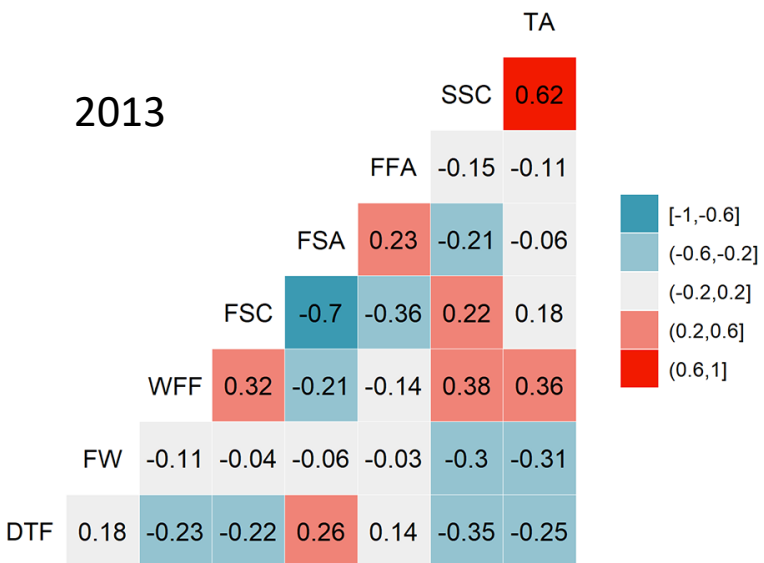

In this equation, $\mathrm{Mean}_{(+)}$and $\mathrm{Mean}_{(-)}$refer to the mean trait values for all lines with and without alleles for the relevant marker peak, respectively. Additionally, $\Delta \mathrm{D}$ represents the allelic effect associated with the relevant marker peak. The significance of allelic effects was assessed by a $t$-test implemented with R software (version 3.4.0) (R core team 2016). Threshold $-\log _{10} P$ values were 1.3 and 2.0 at $5 \%$ and $1 \%$ levels, respectively. To characterize the selection effect, cluster analysis (Ward method) was performed using $\Delta \mathrm{D}$ as explanatory values.

\section{Results}

\section{Correlation of strawberry fruit quality-related traits}

Before GWAS, we evaluated Pearson's correlation coefficients of 10 measured fruit quality-related traits for the experimental years (Table 1). Among 10 traits, FW, FSC, WFF, FSF, FFF, and FSA showed relatively higher correlations, while the correlation coefficient of DTF was the lowest. Other traits such as SSC, TA, and FFA indicated moderate correlations. Correlations among eight traits (DTF, FW, FSC, WFF, SSC, TA, FSA, and FFA) are shown in Figure 1. Fruit colorrelated traits (FSC, FSA, FFA) were correlated with

Table 1. Inter-year correlation coefficients of fruit quality-related traits using the strawberry MAGIC population in multiple years.

\begin{tabular}{lc}
\hline \multicolumn{1}{c}{ Trait name } & Correlation coefficients \\
\hline Fruit weight & $0.51-0.62$ \\
Fruit surface color & $0.57-0.66$ \\
Whole fruit firmness & $0.51-0.62$ \\
Days to flowering & $0.16-0.36$ \\
Fruit surface firmness & $0.51-0.64$ \\
Fruit flesh firmness & $0.37-0.63$ \\
Soluble solid content & $0.29-0.43$ \\
Titratable acidity & $0.22-0.53$ \\
Fruit surface anthocyanin & $0.43-0.59$ \\
Fruit flesh anthocyanin & $0.27-0.40$ \\
\hline
\end{tabular}

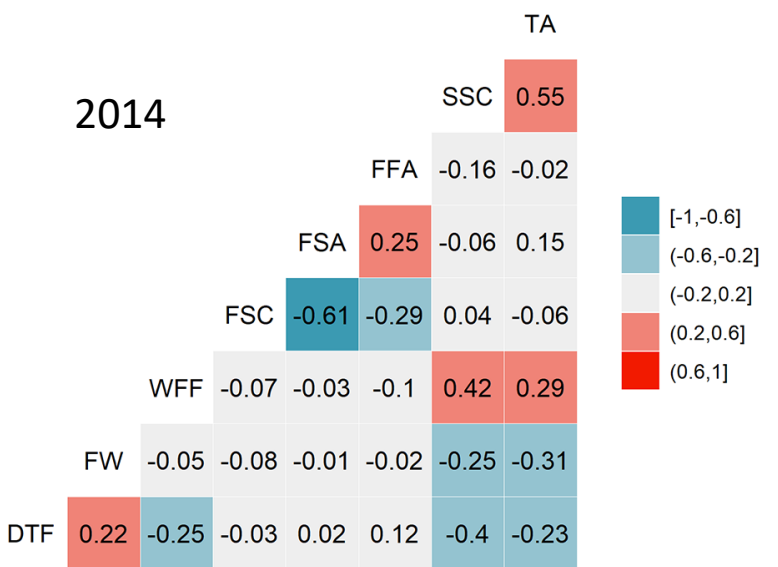

Fig. 1. Correlation coefficients among eight kinds of fruit quality-related traits of the MAGIC population in 2013 and 2014. 
each other, but did not show any higher correlation with other traits (DTF, FW, WFF, SSC, TA), while DTF, FW, WFF, SSC, TA were correlated with each other.

Comparison of QTLs detected by GWAS with and without correction of population structure, which was evaluated with PCA

Genotyping with 336 EST-SSR markers detected 1,343 polymorphic loci. Fundamental statistics for the examined traits are listed in Table S2. We focused on fruit quality-related traits for the MAGIC population using available genotypes and phenotypes, and performed GWAS using GLM with and without correction for population structure (Table 2). The number of QTLs for FSF was the highest among 13 fruit quality-related traits, and that for WFF was the second highest. QTLs for GC and FC were not detected. Comparisons of GWAS with and without correction of population structure revealed that almost all significant markers were common, and QTLs for FW, FFF, SSC, TA, FSA, and FFA of both analyses were identical. Therefore, QTLs with correction of population structure were listed in the following section.

\section{QTLs for fruit quality-related traits}

Totally, 165 QTLs for fruit quality-related traits were detected using a MAGIC population.

We detected only two QTLs for FW as shown in Table 3. Five QTLs for FSC were detected (Table 4), and 38 QTLs for WFF (Table 5). Similarly, 48 QTLs for FSF were detected (Table S4), but only 13 QTLs for
FFF (Table S5). Common flanking markers were detected in WFF and FSF (e.g. FVES1692 279, FAES0454_405, FVES0175_210, FVES0662_537, and FVES0962_156). Additionally, 21 QTLs were detected for DTF (Table S3), nine for SSC (Table S6), eight for TA (Table S7), 12 for FSA (Table S8), and five for FFA

Table 2. Comparison of QTLs detected by GWAS with and without correction of population structure evaluated with PCA.

\begin{tabular}{|c|c|c|c|c|}
\hline \multirow{3}{*}{ No. } & \multirow{3}{*}{ Trait } & \multicolumn{3}{|c|}{$\begin{array}{c}\text { Number of significant markers } \\
\text { in GWAS }\end{array}$} \\
\hline & & \multicolumn{2}{|c|}{ Population structure } & \multirow{2}{*}{$\begin{array}{c}\text { Common } \\
\text { markers }\end{array}$} \\
\hline & & $t^{z}$ & $-\mathrm{z}$ & \\
\hline 1 & Fruit weight & 3 & 3 & 3 \\
\hline 2 & Fruit surface color & 6 & 7 & 5 \\
\hline 3 & Whole fruit firmness & 57 & 58 & 55 \\
\hline 4 & Days to flowering & 29 & 30 & 28 \\
\hline 5 & Fruit surface firmness & 73 & 75 & 72 \\
\hline 6 & Fruit flesh firmness & 21 & 21 & 21 \\
\hline 7 & Soluble solid content & 12 & 12 & 12 \\
\hline 8 & Titratable acidity & 8 & 8 & 8 \\
\hline 9 & Fruit surface anthocyanin & 17 & 17 & 17 \\
\hline 10 & Fruit flesh anthocyanin & 7 & 7 & 7 \\
\hline 11 & Sucrose content & 4 & 2 & 2 \\
\hline 12 & Glucose content & 0 & 0 & 0 \\
\hline \multirow[t]{2}{*}{13} & Fructose content & 0 & 0 & 0 \\
\hline & Total & 237 & 240 & 230 \\
\hline
\end{tabular}

z '+' and '-' signs indicate GWAS with and without correction of population structure, respectively.

Table 3. QTLs for fruit weight detected by GWAS using the strawberry MAGIC population.

\begin{tabular}{clcccccc}
\hline \hline \multirow{2}{*}{ QTL $^{z}$} & \multirow{2}{*}{ Marker $^{y}$} & \multicolumn{7}{c}{$-\log _{10} P^{\mathrm{x}}$} \\
\cline { 3 - 8 } & & Avg. & 2013 & 2014 & 2015 & 2016 & 2017 \\
\hline \multirow{2}{*}{ qFW1 } & FVES2914_352 & 5.10 & 2.77 & 3.02 & 2.76 & 2.41 & 4.06 \\
\multirow{2}{*}{ qFW2 } & FVES0181_225 & 4.83 & 2.76 & 3.58 & 2.38 & 2.19 & 3.78 \\
& FVES3769_299 & 5.67 & 3.19 & 5.30 & 1.94 & 3.05 & 3.66 \\
\hline
\end{tabular}

z Markers with $P$ values exceeding the GWAS threshold level using average trait values are listed based on the assumption that there were QTLs in the vicinity of relevant markers.

${ }^{y}$ The last number of the marker name shows the size of the PCR amplicon (bp).

${ }^{x}$ Avg. implies the $-\log P$ value of the relevant SSR marker based on GWAS using average trait values from 2013 to 2017.

Table 4. QTLs for fruit surface color detected by GWAS using the strawberry MAGIC population.

\begin{tabular}{clcccccc}
\hline \hline \multirow{2}{*}{ QTL $^{z}$} & \multirow{2}{*}{ Marker } & \multicolumn{5}{c}{$-\log _{10} P^{\mathrm{x}}$} \\
\cline { 3 - 8 } & & Avg. & 2013 & 2014 & 2015 & 2016 & 2017 \\
\hline qFSC1 & FVES0319_227 & 4.91 & 1.70 & 5.32 & 3.20 & 2.92 & 3.51 \\
\hline qFSC2 & FVES3027_411 & 5.35 & 2.73 & 3.91 & 2.56 & 3.81 & 4.92 \\
\hline \multirow{2}{*}{ qFSC3 } & FVES3528_202 & 6.80 & 5.82 & 6.49 & 1.35 & 5.56 & 4.16 \\
& FVES0380_305 & 6.70 & 5.84 & 6.78 & 2.51 & 5.64 & 2.78 \\
qFSC4 & FVES3528_205 & 5.05 & 4.12 & 4.56 & 1.85 & 2.86 & 3.60 \\
qFSC5 & FVES1687_184 & 6.12 & 4.59 & 3.98 & 3.62 & 3.58 & 3.91 \\
\hline
\end{tabular}

Superscript letters are the same as for Table 3. 
Table 5. QTLs for whole fruit firmness detected by GWAS using the strawberry MAGIC population.

\begin{tabular}{|c|c|c|c|c|c|}
\hline \multirow{2}{*}{$\mathrm{QTL}^{\mathrm{z}}$} & \multirow{2}{*}{ Marker $^{\mathrm{y}}$} & \multicolumn{4}{|c|}{$-\log _{10} P^{\mathrm{x}}$} \\
\hline & & Avg. & 2013 & 2014 & 2017 \\
\hline \multirow{2}{*}{ qWFF1 } & FVES1692_279 & 7.61 & 4.46 & 6.72 & 3.58 \\
\hline & FAES0454_405 & 7.27 & 4.37 & 6.44 & 3.25 \\
\hline \multirow{3}{*}{ qWFF2 } & FVES0175_210 & 7.39 & 3.65 & 7.02 & 3.79 \\
\hline & FVES0662_537 & 7.12 & 2.86 & 7.08 & 4.03 \\
\hline & FVES0962_156 & 8.45 & 4.24 & 8.22 & 4.19 \\
\hline \multirow{3}{*}{ qWFF3 } & FVES1286_313 & 8.68 & 5.73 & 7.70 & 3.93 \\
\hline & FVES3100_224 & 7.18 & 5.26 & 5.95 & 3.00 \\
\hline & FAES0352_405 & 5.03 & 5.39 & 4.27 & 1.79 \\
\hline qWFF4 & FVES0849_301 & 6.46 & 8.76 & 3.59 & 1.47 \\
\hline qWFF5 & FVES0392_131 & 6.18 & 3.18 & 4.15 & 5.81 \\
\hline qWFF6 & FAES0071_143 & 4.95 & 6.22 & 3.13 & 0.71 \\
\hline \multirow{2}{*}{ qWFF7 } & FVES0795_236 & 5.96 & 5.60 & 4.06 & 3.39 \\
\hline & FVES0048_212 & 7.34 & 6.45 & 5.60 & 3.66 \\
\hline qWFF8 & FVES0646_186 & 5.28 & 3.24 & 4.92 & 3.33 \\
\hline \multirow{2}{*}{ qWFF9 } & FVES2110_232 & 5.43 & 5.23 & 3.63 & 1.96 \\
\hline & FAES0202_187 & 5.39 & 5.17 & 3.62 & 1.89 \\
\hline qWFF10 & FAES0202_178 & 7.15 & 4.52 & 5.45 & 4.41 \\
\hline \multirow{2}{*}{ qWFF11 } & FVES1230_170 & 5.07 & 4.73 & 4.15 & 1.00 \\
\hline & FVES0100_207 & 4.92 & 4.10 & 4.07 & 1.24 \\
\hline \multirow{2}{*}{ qWFF12 } & FAES0065_321 & 5.07 & 5.39 & 3.24 & 1.90 \\
\hline & FVES0224_146 & 4.49 & 4.89 & 3.01 & 1.49 \\
\hline qWFF13 & FVES2592_397 & 4.45 & 3.69 & 3.51 & 2.87 \\
\hline \multirow{2}{*}{ qWFF14 } & FVES1512_295 & 5.93 & 3.84 & 5.15 & 2.74 \\
\hline & FVES0008_293 & 5.93 & 3.77 & 5.19 & 2.74 \\
\hline qWFF15 & FVES0008_281 & 4.60 & 2.55 & 5.29 & 2.02 \\
\hline qWFF16 & FVES1868_270 & 7.82 & 8.98 & 3.61 & 4.98 \\
\hline qWFF17 & FVES0213_307 & 4.45 & 4.48 & 4.64 & 2.36 \\
\hline \multirow{2}{*}{ qWFF18 } & FVES0495_287 & 4.94 & 5.08 & 3.51 & 1.90 \\
\hline & FVES0495_299 & 4.72 & 4.83 & 3.36 & 1.80 \\
\hline qWFF19 & FVES1534_172 & 4.68 & 5.00 & 3.40 & 2.90 \\
\hline qWFF20 & FAES0085_242 & 6.46 & 8.76 & 3.59 & 1.47 \\
\hline qWFF21 & FVES0373_109 & 4.83 & 3.12 & 4.64 & 2.68 \\
\hline qWFF22 & FVES0504_190 & 7.10 & 6.27 & 2.29 & 6.39 \\
\hline \multirow{4}{*}{ qWFF23 } & FVES0478_305 & 4.86 & 2.94 & 4.65 & 3.24 \\
\hline & FAES0105_137 & 4.86 & 2.94 & 4.65 & 3.24 \\
\hline & FVES0130_274 & 4.86 & 2.94 & 4.65 & 3.24 \\
\hline & FVES2707_205 & 4.79 & 2.94 & 4.77 & 3.01 \\
\hline \multirow{2}{*}{ qWFF24 } & FVES1595_328 & 4.45 & 3.59 & 2.67 & 3.48 \\
\hline & FVES2185_246 & 4.45 & 3.59 & 2.67 & 3.48 \\
\hline \multirow{2}{*}{ qWFF25 } & FVES0670_344 & 6.72 & 9.04 & 3.82 & 1.54 \\
\hline & FVES0519_171 & 6.72 & 9.04 & 3.82 & 1.54 \\
\hline qWFF26 & FVES0686_203 & 4.88 & 1.62 & 5.70 & 2.48 \\
\hline qWFF27 & FVES1379_424 & 4.56 & 2.89 & 1.96 & 5.73 \\
\hline qWFF28 & FVES0119_245 & 6.20 & 2.94 & 6.33 & 4.41 \\
\hline \multirow{3}{*}{ qWFF29 } & FVES3101_255 & 4.91 & 3.38 & 2.06 & 5.90 \\
\hline & FVES1396_269 & 4.91 & 3.38 & 2.06 & 5.90 \\
\hline & FVES0195_288 & 4.94 & 3.40 & 2.07 & 5.90 \\
\hline qWFF30 & FVES3051_440 & 7.48 & 5.17 & 3.27 & 7.21 \\
\hline qWFF31 & FVES0118_248 & 5.25 & 6.12 & 2.66 & 3.67 \\
\hline qWFF32 & FVES0192_181 & 5.26 & 5.96 & 1.76 & 5.84 \\
\hline qWFF33 & FVES3232_242 & 4.64 & 2.98 & 3.29 & 4.56 \\
\hline qWFF34 & FAES0049_171 & 4.80 & 5.23 & 3.05 & 3.38 \\
\hline qWFF35 & FVES0027_235 & 5.53 & 4.83 & 3.78 & 4.92 \\
\hline qWFF36 & FVES1889_190 & 5.66 & 2.63 & 6.50 & 4.88 \\
\hline \multirow{2}{*}{ qWFF37 } & FVES3183_289 & 5.88 & 3.41 & 5.41 & 4.34 \\
\hline & FVES0190_236 & 5.88 & 3.32 & 5.08 & 4.46 \\
\hline qWFF38 & FVES0171_265 & 4.60 & 4.11 & 2.57 & 3.72 \\
\hline
\end{tabular}

Superscript letters are the same as for Table 3. 
(Table S9). Among individual sugar contents (SC, GC, and FC), only four QTLs for SC were detected (Table S10); no significant QTLs for GC and FC were detected.

\section{Allelic effect of QTLs for FW, FSC, and WFF}

Focusing on the mean values of each allele group of significant markers and genotypes of the six founder parents, allelic effects of QTLs were evaluated. Flanking markers of QTLs for FW, FVES2914_352, and FVES0181_225, showed that the presence of the marker peak was correlated with positive trait values of $\mathrm{FW}$ (Table 6). On the other hand, five markers
(FVES0459_262, FVES3027_411， FVES3528_202, FVES0380 305, and FVES1687 184) out of seven indicated that the absence of the marker peak was correlated with a deeper red color (Table 7). A similar tendency was detected in WFF, where the absence of a marker peak was seen in nine out of 10 markers, and this was correlated with hardening fruit firmness (Table 8). Although the absence of a marker peak was correlated with positive trait values in FVES1868_270, polymorphic alleles were not detected among the six founder parents.

Table 6. Allelic effect of QTLs for fruit weight.

\begin{tabular}{|c|c|c|c|c|c|c|c|c|c|}
\hline \multirow{2}{*}{ Marker } & \multicolumn{2}{|c|}{$\mathrm{FSC}^{\mathrm{z}}$} & \multirow{2}{*}{$\begin{array}{c}\text { Preferable } \\
\text { allele }\end{array}$} & \multirow{2}{*}{$\begin{array}{c}06 \mathrm{~A}-184^{\mathrm{y}} \\
(27.8 \mathrm{~g})\end{array}$} & \multirow{2}{*}{$\begin{array}{c}\text { Fukuoka S6 } \\
\quad(30.1 \mathrm{~g})\end{array}$} & \multirow{2}{*}{$\begin{array}{c}\text { Benihoppe } \\
(26.8 \mathrm{~g})\end{array}$} & \multirow{2}{*}{$\begin{array}{l}\text { Kaorino } \\
(17.4 \mathrm{~g})\end{array}$} & \multirow{2}{*}{$\begin{array}{l}\text { Ookimi } \\
(26.5 \mathrm{~g})\end{array}$} & \multirow{2}{*}{$\begin{array}{c}\text { Sachinoka } \\
(21.8 \mathrm{~g})\end{array}$} \\
\hline & Allele_A & Allele_P & & & & & & & \\
\hline FVES2914_352 & 19.1 & 21.9 & $\mathrm{P}$ & $\mathrm{P}$ & $\mathrm{P}$ & A & A & $\mathrm{P}$ & $\mathrm{P}$ \\
\hline FVES0181_225 & 19.1 & 21.9 & $\mathrm{P}$ & $\mathrm{P}$ & $\mathrm{P}$ & $\mathrm{A}$ & $\mathrm{A}$ & $\mathrm{P}$ & $\mathrm{P}$ \\
\hline
\end{tabular}

${ }^{z}$ Numerical values in the Founder show the average FW of relevant parental cultivars. White characters on a gray background imply positive alleles for trait values. A and P represent absence and presence of relevant SSR marker peaks in fragment analysis, respectively.

y Numerical values indicate the average FW of MAGIC population plants that harbored relevant alleles.

Table 7. Allelic effect of QTLs on fruit surface color.

\begin{tabular}{|c|c|c|c|c|c|c|c|c|c|}
\hline \multirow{2}{*}{ Marker } & \multicolumn{2}{|c|}{$\mathrm{FSC}^{\mathrm{z}}$} & \multirow{2}{*}{$\begin{array}{l}\text { Preferable } \\
\text { allele }\end{array}$} & \multirow{2}{*}{$\begin{array}{c}\text { 06A-184y } \\
(22.2)\end{array}$} & \multirow{2}{*}{$\begin{array}{c}\text { Fukuoka S6 } \\
\quad(20.3)\end{array}$} & \multirow{2}{*}{$\begin{array}{c}\text { Benihoppe } \\
(25.1)\end{array}$} & \multirow{2}{*}{$\begin{array}{c}\text { Kaorino } \\
(29.1)\end{array}$} & \multirow{2}{*}{$\begin{array}{c}\text { Ookimi } \\
(31.6)\end{array}$} & \multirow{2}{*}{$\begin{array}{c}\text { Sachinoka } \\
\quad(20.6)\end{array}$} \\
\hline & Allele_A & Allele_P & & & & & & & \\
\hline FVES0319_227 & 26.0 & 22.7 & $\mathrm{P}$ & $\mathrm{P}$ & $\mathrm{P}$ & A & A & A & $\mathrm{A}$ \\
\hline FVES0459_262 & 24.6 & 26.5 & A & A & $\mathrm{P}$ & A & $\mathrm{P}$ & $P$ & A \\
\hline FVES3027_411 & 23.5 & 26.2 & A & A & $\mathrm{P}$ & $\mathrm{P}$ & $\mathrm{P}$ & $\mathrm{P}$ & $P$ \\
\hline FVES3528_202 & 23.5 & 26.4 & A & $\mathrm{P}$ & A & $\mathrm{P}$ & $\mathrm{P}$ & $\mathrm{P}$ & $\mathrm{P}$ \\
\hline FVES0380_305 & 23.8 & 26.4 & A & $P$ & A & $P$ & $P$ & $\mathrm{P}$ & $P$ \\
\hline FVES3528_205 & 26.5 & 24.5 & $\mathrm{P}$ & $P$ & $P$ & A & A & $\mathrm{P}$ & $P$ \\
\hline FVES1687_184 & 24.6 & 26.8 & A & $P$ & A & $P$ & $\mathrm{P}$ & $P$ & A \\
\hline
\end{tabular}

${ }^{\mathrm{z}}$ Numerical values in the Founder show the average FSC of relevant parental cultivars. White characters on a gray background imply positive alleles for trait values. A and P represent absence and presence of relevant SSR marker peaks in fragment analysis, respectively.

${ }^{y}$ Numerical values indicate the average FSC of MAGIC population plants that harbored relevant alleles.

Table 8. Allelic effect of QTLs for whole fruit firmness.

\begin{tabular}{|c|c|c|c|c|c|c|c|c|c|}
\hline \multirow{2}{*}{ Marker } & \multicolumn{2}{|c|}{ WFF $(\mathrm{gF})^{\mathrm{z}}$} & \multirow{2}{*}{$\begin{array}{l}\text { Preferable } \\
\text { allele }\end{array}$} & \multirow{2}{*}{$\begin{array}{c}06 \mathrm{~A}-184^{\mathrm{y}} \\
(88 \mathrm{gF})\end{array}$} & \multirow{2}{*}{$\begin{array}{c}\text { Fukuoka S6 } \\
\quad(96 \mathrm{gF})\end{array}$} & \multirow{2}{*}{$\begin{array}{c}\text { Benihoppe } \\
(106 \mathrm{gF})\end{array}$} & \multirow{2}{*}{$\begin{array}{c}\text { Kaorino } \\
(87 \mathrm{gF})\end{array}$} & \multirow{2}{*}{$\begin{array}{c}\text { Ookimi } \\
(128 \mathrm{gF})\end{array}$} & \multirow{2}{*}{$\begin{array}{c}\text { Sachinoka } \\
(117 \mathrm{gF})\end{array}$} \\
\hline & Allele_A & Allele_P & & & & & & & \\
\hline FVES1286_313 & 110 & 90 & A & $\mathrm{P}$ & $\mathrm{P}$ & A & $\mathrm{P}$ & $\mathrm{P}$ & $\mathrm{P}$ \\
\hline FVES0962_156 & 108 & 89 & A & $\mathrm{P}$ & $\mathrm{P}$ & A & $\mathrm{P}$ & $\mathrm{P}$ & A \\
\hline FVES1868_270 & 133 & 92 & A & $\mathrm{P}$ & $\mathrm{P}$ & $\mathrm{P}$ & $\mathrm{P}$ & $\mathrm{P}$ & $\mathrm{P}$ \\
\hline FVES1692_279 & 108 & 90 & A & $\mathrm{P}$ & $\mathrm{P}$ & A & $\mathrm{P}$ & $\mathrm{P}$ & A \\
\hline FVES3051_440 & 106 & 90 & A & $\mathrm{P}$ & A & $\mathrm{P}$ & $\mathrm{P}$ & A & $\mathrm{P}$ \\
\hline FVES3100_224 & 109 & 90 & A & $P$ & $P$ & A & $P$ & $\mathrm{P}$ & $\mathrm{P}$ \\
\hline FVES0048_212 & 91 & 110 & $\mathrm{P}$ & A & A & A & A & $\mathrm{P}$ & A \\
\hline FAES0202_178 & 119 & 92 & A & $\mathrm{P}$ & $\mathrm{P}$ & A & $\mathrm{P}$ & $\mathrm{P}$ & $\mathrm{P}$ \\
\hline FVES0504_190 & 113 & 91 & A & $\mathrm{P}$ & $\mathrm{P}$ & $\mathrm{P}$ & $\mathrm{P}$ & A & $\mathrm{P}$ \\
\hline FVES0670_344 & 101 & 87 & A & A & $P$ & $P$ & A & A & $\mathrm{P}$ \\
\hline
\end{tabular}

${ }^{z}$ Numerical values in the Founder show the average WFF of relevant parental cultivars. White characters on a gray background imply positive alleles for trait values. A and P represent absence and presence of relevant SSR marker peaks in fragment analysis, respectively.

${ }^{y}$ Numerical values indicate the average WFF of MAGIC population plants that harbored relevant alleles. 
Selection of candidate SSR markers for marker-assisted breeding for strawberry fruit quality-related traits

Throughout GWAS for strawberry fruit qualityrelated traits, some markers were shared as flanking markers for multiple QTLs (Table 9). FVES0048_212 was selected as a flanking marker of QTLs for WFF, FSF, SSC, FSC, FSA, and FAA. The presence of an allele of this marker increased fruit firmness (WFF and FSF), but lightened fruit color (FSC, FSA, and FFA). A similar effect was detected in FVES0419_116, FVES1125_286, FVES1692_324, and FVES1868_270, although the differences in some traits were not significant by $t$-test. Allelic differences in FVES0380 305 and FVES1687_184, which were detected as flanking markers of QTLs for fruit color-related traits (FSC, FSA, and FFA), did not affect fruit firmness-related traits (WFF, FSF, and FFF), SSC, or TA. SSC and TA most frequently shared significant markers, FVES0419 116, FVES0171_265, FVES0987_191, FVES1125_286, and
FVES1868_270. Additionally, positive alleles to improve SSC and TA were also shared in those SSR markers.

Based on the $\Delta \mathrm{D}$ values of selected SSR markers listed in Table 9, cluster analysis was performed to characterize the allelic effect. Nine selected markers were classified into two groups: Group 1 was composed of four markers, FVES1125_286, FVES0987_191, FVES0419_116, and FVES1868_270. Group 2 contained five markers, FVES1687 184, FVES0380 305, FVES0048_212, FVES1692_324, and FVES0171_265 (Fig. 2). Based on the primer sequences of the nine selected markers, we searched the corresponding chromosome regions of the Fragaria vesca genome v2.0.a1 and Fragaria $\times$ ananassa Camarosa genome v1.0 pseudomolecules, and listed the results in Figure 2. The primer sequences of SSR markers in Group 1 were derived from chromosomes 3,5 , and 6 of $F$. vesca, which corresponded to Fvb3-1, 5-1, and 6-1 of $F$. $\times$ ananassa.

Table 9. SSR markers significantly detected in multiple fruit quality traits and the allelic effects on various fruit quality traits.

\begin{tabular}{|c|c|c|c|c|c|c|c|c|c|c|c|}
\hline Group $^{z}$ & Marker Name & $\begin{array}{l}\mathrm{DTF}^{\mathrm{y}} \\
\text { (days) }\end{array}$ & $\begin{array}{r}\text { FW } \\
(\mathrm{g})\end{array}$ & $\begin{array}{l}\text { WFF } \\
(\mathrm{gF})\end{array}$ & $\begin{array}{l}\text { FSF } \\
(\mathrm{gF})\end{array}$ & $\begin{array}{l}\text { FFF } \\
(\mathrm{gF})\end{array}$ & $\begin{array}{l}\text { SSC } \\
(\%)\end{array}$ & $\begin{array}{l}\text { TA } \\
(\%)\end{array}$ & $\begin{array}{c}\text { FSC } \\
\left(L^{*} \cdot b^{*} / a^{*}\right)\end{array}$ & $\begin{array}{c}\text { FSA } \\
\left(\mu \mathrm{g} \cdot \mathrm{g}^{-1} \mathrm{FW}\right)(\mu \mathrm{g}\end{array}$ & $\begin{array}{c}\text { FFA } \\
\left.\mathrm{g} \cdot \mathrm{g}^{-1} \mathrm{FW}\right)\end{array}$ \\
\hline A & & 54.8 & 20.5 & 91 & 66 & 25 & 8.69 & 0.61 & 25.3 & 1491 & 125 \\
\hline $\mathrm{P}$ & FVES0048_212 & 50.6 & 21.5 & 110 & 84 & 26 & 9.52 & 0.63 & 27.6 & 1117 & 61 \\
\hline sig. & & NS & NS & $* * *$ & $* * *$ & NS & $* * *$ & NS & $* * *$ & $* * *$ & $* * *$ \\
\hline A & & 53.5 & 19.6 & 96 & 72 & 24 & 8.75 & 0.63 & 23.8 & 1595 & 160 \\
\hline $\mathrm{P}$ & FVES0380_305 & 54.3 & 21.2 & 93 & 68 & 25 & 8.84 & 0.61 & 26.4 & 1372 & 98 \\
\hline sig. & & NS & $*$ & NS & NS & NS & NS & NS & $* * *$ & $* * *$ & $* * *$ \\
\hline A & & 55.5 & 19.8 & 92 & 68 & 24 & 8.72 & 0.62 & 24.6 & 1553 & 137 \\
\hline $\mathrm{P}$ & FVES1687_184 & 52.8 & 21.4 & 95 & 70 & 25 & 8.91 & 0.61 & 26.8 & 1321 & 95 \\
\hline sig. & & NS & $*$ & NS & NS & NS & NS & NS & $* * *$ & $* * *$ & $* * *$ \\
\hline A & & 52.0 & 20.7 & 96 & 71 & 25 & 8.94 & 0.61 & 26.1 & 1364 & 100 \\
\hline $\mathrm{P}$ & FVES0419_116 & 61.3 & 20.5 & 88 & 64 & 24 & 8.45 & 0.63 & 24.6 & 1634 & 160 \\
\hline sig. & & $* * *$ & NS & $*$ & $*$ & NS & $* *$ & $*$ & $* *$ & $* * *$ & $* * *$ \\
\hline A & & 55.7 & 21.2 & 89 & 64 & 25 & 8.54 & 0.59 & 25.5 & 1488 & 122 \\
\hline $\mathrm{P}$ & FVES0171_265 & 52.3 & 20.1 & 100 & 75 & 25 & 9.13 & 0.64 & 26.0 & 1361 & 107 \\
\hline sig. & & $*$ & NS & $* * *$ & $* * *$ & NS & $* * *$ & $* * *$ & NS & $*$ & NS \\
\hline A & & 54.3 & 20.0 & 95 & 69 & 26 & 9.17 & 0.64 & 26.3 & 1393 & 106 \\
\hline $\mathrm{P}$ & FVES0987_191 & 53.8 & 21.6 & 93 & 69 & 24 & 8.40 & 0.58 & 25.0 & 1470 & 125 \\
\hline sig. & & NS & $*$ & NS & NS & $* *$ & $* * *$ & $* * *$ & $* *$ & NS & NS \\
\hline A & & 54.7 & 20.0 & 98 & 72 & 26 & 9.03 & 0.62 & 25.8 & 1447 & 116 \\
\hline $\mathrm{P}$ & FVES1125_286 & 52.8 & 22.0 & 87 & 64 & 22 & 8.41 & 0.59 & 25.7 & 1391 & 112 \\
\hline sig. & & NS & $* *$ & $* * *$ & $* *$ & $* * *$ & $* * *$ & $* *$ & NS & NS & NS \\
\hline A & & 55.2 & 21.5 & 90 & 66 & 24 & 8.57 & 0.61 & 25.6 & 1467 & 121 \\
\hline $\mathrm{P}$ & FVES1692_324 & 52.0 & 19.2 & 102 & 76 & 26 & 9.31 & 0.63 & 26.1 & 1351 & 102 \\
\hline sig. & & NS & $* * *$ & $* * *$ & $* * *$ & $*$ & $* * *$ & NS & NS & $*$ & NS \\
\hline A & & 43.6 & 17.8 & 133 & 103 & 30 & 10.71 & 0.68 & 26.6 & 1203 & 91 \\
\hline $\mathrm{P}$ & FVES1868_270 & 54.5 & 20.8 & 92 & 68 & 25 & 8.75 & 0.61 & 25.7 & 1436 & 115 \\
\hline sig. & & $*$ & NS & $* * *$ & $* * *$ & $* *$ & $* * *$ & $*$ & NS & NS & NS \\
\hline
\end{tabular}

z Trait values of Group A and Group_P indicate averages of MAGIC population plants in which relevant SSR marker peaks were absent and present, respectively. *,*, and *** in the row of 'sig.' imply that the difference in average values was significant at $5 \%, 1 \%$, and $0.1 \%$ level, respectively, by $t$-test. 'NS' means not significant. Group numbers ' 1 ' and ' 2 ' should be referenced to Figure 2.

${ }^{y}$ Trait values and significance signals with gray backgrounds imply that QTLs were detected in the relevant trait through GWAS. 
Those in Group 2 from chromosome 1, 2, and 7, of $F$. vesca corresponded to Fvb1-4, 2-2, and 7-2 of $F$. $\times$ ananassa. Average $\Delta \mathrm{D}$ values of the two groups are shown in Figure 3. Focusing on Group 1, recessive alleles tended to show a lower DTF, FW, FSA, and FFA, and a higher WFF, FSF, FFF, SSC, TA, and FSC compared with the dominant allele. In Group 2, allelic differences were mainly observed in fruit color-related traits (FSC, FSA, and FFA) and hardly affected any other traits, but the tendency was symmetrical to Group 1 (Fig. 3).

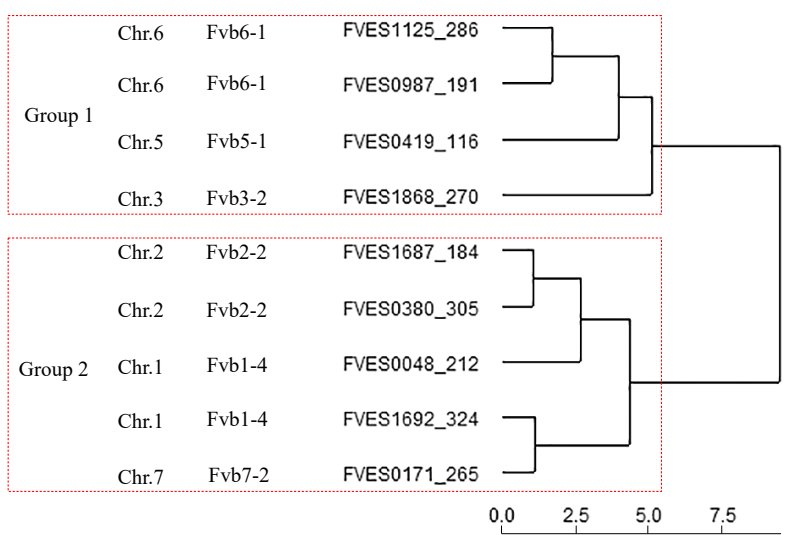

Fig. 2. Classification of selected markers by cluster analysis (Ward method) based on the allelic effect for fruit quality trait values. The numbers for 'Chr.' and 'Fvb' indicate the chromosome regions from which the relevant SSR markers were derived on the Fragaria vesca genome v2.0.a1 and Camarosa genome v1.0 pseudomolecules, respectively.
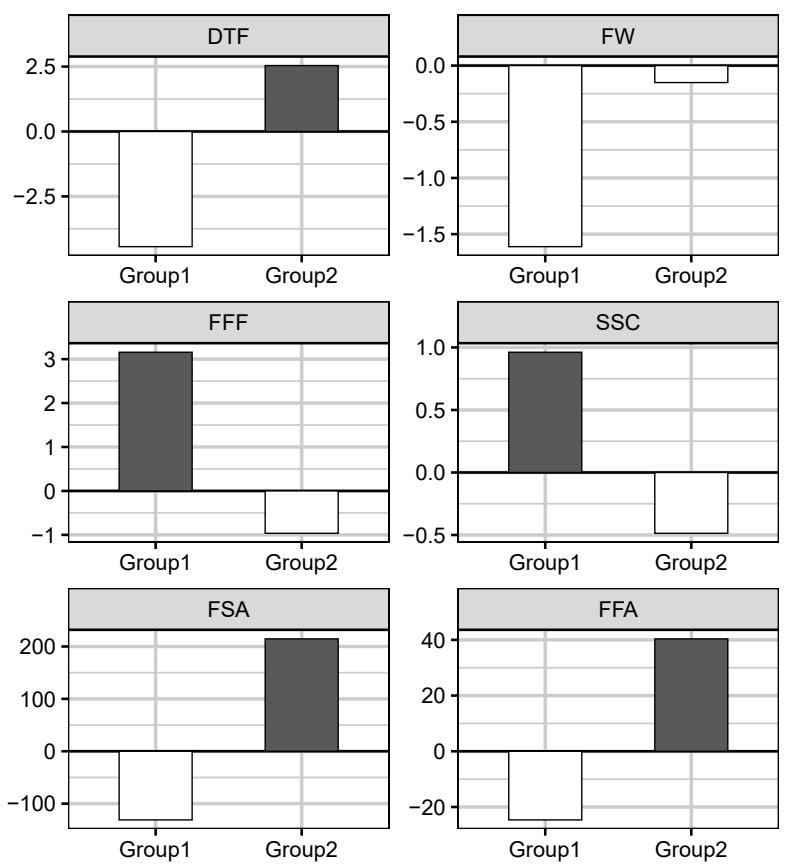

Fig. 3. Average $\Delta \mathrm{D}$ values of three marker groups based on the classification of selected markers by cluster analysis. $\Delta \mathrm{D}$, which indicates the difference in mean trait values between plants with a ' + ' allele and those with a ' - ' allele of each marker, represents the allelic effect of the relevant marker. Average $\Delta \mathrm{D}$ values were mean values of all markers that belonged to each group. Plus values (pink) and minus values (blue) of $\Delta \mathrm{D}$ indicated that allele $(-)$ and allele $(+)$ increased the relevant trait values, respectively.
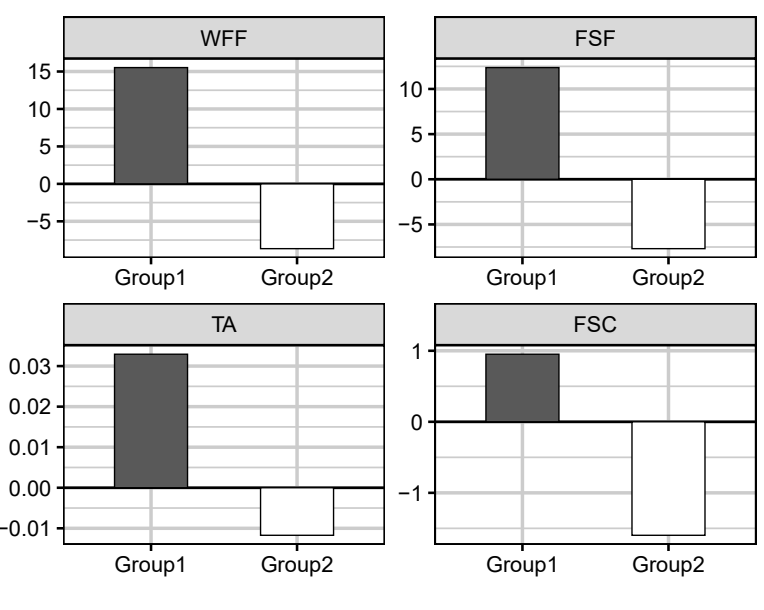

\section{Discussion}

In this study, we performed a GWAS of 13 fruit quality-related traits using a strawberry MAGIC population derived from six cultivars. Before conducting GWAS, we evaluated correlations among fruit qualityrelated traits, which revealed that fruit color-related traits (FSC, FSA, and FFA) showed relatively higher inter-year correlation and lower correlation with other traits, such as DTF, FW, WFF, SSC, and TA. These results strongly suggested that fruit color of cultivated strawberry was not affected by the fluctuation of other traits, and that it was controlled with genes independent from those for other traits. Comparing the results of two kinds of GWAS using GLM with and without correction for population structure demonstrated that almost all QTLs of both approaches were the same. This result fully supported our previous study (Wada et al., 2017), which indicated that our MAGIC population was an almost even mosaic of six founder parents. GWAS taking into account the population structure revealed a large number of QTLs, including 21 QTLs for DTF, two for FW, five for FSC, 38 for WFF, 47 for FSF, 13 for FFF, nine for SSC, eight for TA, 12 for FSA, five for FFA, and four for SC. QTLs for GC and FC were not detected. Zorrilla-Fontanesi et al. (2011) previously conducted a QTL analysis of 17 agronomic and fruit quality traits and detected 33 QTLs for almost all traits (Zorrilla-Fontanesi et al., 2011), while LerceteauKöhler et al. (2012) detected as many as 87 QTLs for 19 fruit quality-related traits. Although we also identi- 
fied many QTLs for various traits, most of them were for fruit firmness (WFF, FSF, and FFF). In contrast, the QTLs detected in the above-mentioned studies were evenly distributed among all traits (Zorrilla-Fontanesi et al., 2011; Lerceteau-Köhler et al., 2012). Our study differed from the previous ones in terms of the experimental sample size. Specifically, the genetic and phenotypic variations may have been greater in our MAGIC population derived from six cultivars than in the biparental populations examined in earlier studies (Huang et al., 2015). Therefore, there may be greater genetic variations for strawberry fruit color and fruit firmness than for the other traits. Future investigations are needed to confirm this possibility.

QTLs for fruit weight, fruit color-related traits, and fruit firmness-related traits

Although FW showed relatively higher correlations among fruit quality-related traits over multiple years in our study, QTLs for FW were detected at only two locations. Lerceteau-Köhler et al. (2012) revealed that FW had a relatively higher correlation than other fruit quality traits, as indicated in this study. Zorrilla-Fontanesi et al. (2011) mapped only one QTL for FW in the vicinity of the DNA marker ChFaM206-216h in two consecutive years, while Verma et al. (2017) also only detected one QTL for fruit weight. Higher inter-year correlation and fewer QTLs for FW, which were revealed by previous studies and the current study, suggested that many minor QTLs with relatively small effects contribute to variations in strawberry fruit weight.

Zorrilla-Fontanesi et al. (2011) mapped QTLs for anthocyanin pigmentation and FSC to common regions in the strawberry genome. Lerceteau-Köhler et al. (2012) also detected common QTLs for both traits. Similarly, we identified five QTLs for FSC, 12 for FSA, and five for FFA. $q F S C 5$ and $q F S A 6$ shared a flanking marker, FVES1687_184 Additionally, qFSC3 and qFFA2 shared the flanking markers FVES3528 202 and FVES0380_305. Strawberry pigmentation in the fruit pericarp and flesh is mainly caused by accumulation of the anthocyanin pelargonidin 3-glucoside (Lukton et al., 1955; Yoshida et al., 2002; Yoshida and Tamura, 2005; da Silva et al., 2007). Yoshida and Tamura (2005) observed similar anthocyanin compositions in the pericarp and flesh, which differed from that in the achene. In studies by Zorrilla-Fontanesi et al. (2011) and Lerceteau-Köhler et al. (2012), anthocyanins were extracted from whole fruits so QTL differences were unclear for FSA and FFA. In contrast, a novel finding of our study is that the genetic regions controlling FSA and FFA differed slightly. It is unclear why our results differed from the previous study (Yoshida and Tamura, 2005), although there were differences in the cultivars analyzed between the two studies, with only one cultivar ('Sachinoka') included in both investigations. Vari- etal differences may have been responsible for the inconsistency in the findings.

The transcription factor FaMYB10 helps regulate the flavonoid/phenylpropanoid pathway and is responsible for fruit pigmentation (Medina-Puche et al., 2014). As well as MYB10, abscisic acid (ABA) is responsible for the accumulation of anthocyanins in ripening strawberry fruits (Jia et al., 2011). The expressions of anthocyanin biosynthesis genes were analyzed, and this revealed that ABA upregulates FaMYB10 expression, resulting in anthocyanin accumulation via the enhanced expression of flavonoid pathway genes (KadomuraIshikawa, 2015). Additional studies will be necessary to characterize the relationships among QTLs detected in this study, ABA signal pathway genes, and anthocyanin biosynthesis-related genes such as MYB10.

Zorrilla-Fontanesi et al. (2011) mapped QTLs for fruit firmness in only one year of a 3-year study, while no QTLs for fruit firmness were detected in the study by Verma et al. (2017). Unlike these previous studies, we identified many QTLs for fruit firmness on all chromosomes. Furthermore, WFF was divided into two components, namely FSF and FFF. We attempted to separately detect QTLs for these three traits. As shown in Table 5 and Supplementary Tables 4 and 5, 38 QTLs for WFF, 47 for FSF, and 13 for FFF were detected. Most of the QTLs for these three traits shared common flanking markers, implying that common genetic regions affect FSF and FFF simultaneously, and also affect WFF. However, some QTLs were detected for only one trait. For example, FVES1125 286, FVES0191 216, and FVES1848 305, which were flanking markers of $q F F F 10$, were not shared by WFF and FSF. This suggested that some genetic regions only affect the accumulation of fruit flesh, not FSF.

Monma et al. (1977) reported that FSF and FFF were not highly correlated $(r=+0.479)$ among 70 strawberry cultivars. These observations indicate that some genetic regions separately control FSF and FFF, while others simultaneously influence both traits. Costa et al. (2010) used an $\mathrm{F}_{1}$ population to map the $M d-P G 1$ locus near a detected QTL for apple fruit firmness. PG1 (polygalacturonase 1) helps degrade the plant cell wall, suggesting that differences in $P G 1$ alleles affect apple, as well as strawberry, fruit firmness. Gene expression analyses of ripening fruits are required for a comprehensive investigation of the relationship between QTLs for fruit firmness and cell wall-degrading enzymes.

In future studies, the allelic effect of each QTL must be taken into account. As we indicated in Tables 8, 9, and 10, allele (-) (absence of an SSR signal peak) was strongly related to the deepening red color of the fruit surface and firmer fruit. This provided further evidence that loss of function of certain genes may be involved in improving trait values. The expression of MYB10 and anthocyanin content were positively correlated (Kadomura-Ishikawa, 2015), but our results suggest 
that other gene(s) restrict the accumulation of anthocyanin or the softening of fruits.

QTLs for days to flowering, soluble solids content, titratable acidity, fruit surface anthocyanin, fruit flesh anthocyanin, sucrose content, glucose content, and fructose content

Although other traits showed a relatively lower correlation than FW, WFF, FSF, FFF, and FSC, many QTLs for these traits were detected. Twenty-one QTLs were detected for DTF, but the $-\log _{10} P$ value of each year was quite low (0-2) except for 2013, and the correlation coefficient was the lowest $(r=0.16-0.36)$ among fruit quality-related DTF traits (Table 1). Regarding the QTLs for DTF, those associated with dayneutral DTF were fully analyzed (Sugimoto et al., 2005; Weebadde et al., 2008; Castro and Lewers, 2016; Honjo et al., 2016). Recently, Verma et al. (2017) detected a stable QTL for DTF on linkage group 4A using $23 \mathrm{~F}_{1}$ families, but this region was close to the ever-bearing gene because their materials were mixed with everbearing cultivars and a June-bearing one. In contrast, all six cultivars used in our study were June-bearing cultivars, so the QTLs obtained here are novel ones for distinguishing the earliness of June-bearing cultivars.

The SSC of strawberry fruit can be expressed as a Brix value and is used as a simplified indicator of sugar content. Ogiwara et al. (1998) determined that sucrose, glucose, and fructose are the major sugars in strawberry fruits, and that there are clear varietal differences in SC, GC, and FC. They also reported that SC, GC, and FC were the same in 'Reikou' and 'Nyoho', whereas the $\mathrm{SC}$ was lower than the GC and FC in 'Hokowase' and 'Toyonoka', implying that varietal differences exist in terms of strawberry sugar composition. ZorrillaFontanesi et al. (2011) detected one common QTL for SSC over two years, and Castro and Lewers (2016) also mapped one common QTL. We detected nine QTLs for SSC, of which $q S S C 8$ corresponded to the QTL for SC, $q S C 2$. Lerceteau-Köhler et al. (2012) detected QTLs for SSC, SC, GC, and FC, but their chromosomal locations differed. $q S S C 8$ and $q S C 2$, which we detected in the MAGIC population, are promising candidate regions controlling the SC of strawberry fruit. Sone et al. (2002) revealed that SC was the highest sugar component of strawberry fruits, and that Japanese strawberry cultivars contained a higher SC than American cultivars, while SC varietal differences were wider among Japanese cultivars than American cultivars. However, we found that SC differences among the MAGIC population were moderate among the three sugar components, with GC showing wider trait variations than SC. Further study is necessary to analyze variations in sugar component compositions and the function of these QTLs.

TA is one of the important components affecting the taste of strawberry fruits. Zorrilla-Fontanesi et al.
(2011) detected QTLs for TA over three consecutive years, while Verma et al. (2017) mapped a QTL for TA on chromosome $2 \mathrm{~A}$ in only one year of a 2-year experiment. Out of eight QTLs detected for TA in our study, seven were detected in 2013 and/or 2014. Specific climate conditions in 2017 may therefore have affected the variation in TA. Focusing on the relationship of QTLs for SSC with those of TA, qSSC8 was found to share the flanking marker FVES0171_265 with qTA8. As indicated in Table 9, the allele increasing trait values of SSC and TA was common (allele ' + '). FVES0171 265, FVES0987 191, FVES1125 286, and FVES1868_270 all showed common effects for differences in trait values.

\section{Multiple effect of QTLs on fruit quality-related traits}

Interactions across multiple traits are also of interest to crop breeders. Since trait values of some traits were correlated with each other as shown in Figure 1, the selection of a specific allele of a certain marker can affect the variation in other traits (Table 9). Moreover, as depicted in Figure 3, a positive allele for fruit firmness could simultaneously improve SSC and TA in Group 1, but it could also lighten the fruit color and reduce the anthocyanin content. On the other hand, in Group 2, a positive allele for fruit color, which can deepen fruit redness, could negatively affect fruit firmness, SSC, and TA (FVES0048 212), or hardly affected these traits (FVES0380_305 and FVES1687_184). Estimated marker positions in Group 1 and Group 2 were different from each other based on the genome sequence of not only $F$. vesca, but also $F$. $\times$ ananassa. These results strongly suggest that improvements in fruit firmness (WFF, FSF, and FFF), SSC, and TA could be relatively easy by marker-assisted selection (MAS), but that improvements in fruit firmness and fruit color would be quite difficult by MAS. Therefore, to deepen fruit color, the selection of markers that only affect fruit color is extremely important. According to Table 9, FVES0380 305 and FVES1687 184 are candidate SSR markers for modifying fruit color without affecting other fruit quality-related traits. Since fragment analysis was workable with at most four kinds of SSR markers, the deliberate combination of the most important SSR markers could lead to efficient MAS in strawberry breeding.

\section{Advantages of a MAGIC population}

Using MAGIC populations for genetic analysis to assess which genes are responsible for agronomic traits has some advantages compared with conventional QTL analysis. Rakshit et al. (2012) compared the map of a MAGIC population with that of a linkage map derived from a bi-parental cross population, and revealed that marker density was higher in the map of the MAGIC population than in that of the bi-parental population. This merit was also validated in wheat (Huang et al., 
2012), rice (Bandillo et al., 2013), and tomato (Pascual et al., 2015), and could be attributed to an increasing number of alleles at the same locus because more than four founder parental lines were used to generate MAGIC populations. One of the other advantages of using a MAGIC population is increasing genetic diversity. Huang et al. (2018) generated a cotton MAGIC population using eight founder parental lines and compared genetic and phenotypic diversity among founder parental lines with that among the descendant MAGIC population. They found that both genetic and phenotypic diversity among the MAGIC population was greater than that among founder parental lines on almost all chromosomes. This larger genetic and phenotypic diversity could lead to efficient discovery of traitresponsible QTLs. Furthermore, Bandillo et al. (2013) generated a rice MAGIC population comprised of eight founder lines, and validated the effect of QTLs for multiple traits, such as resistance to biotic stress (blast and bacterial blight), resistance to abiotic stress (salt stress and submergence), and grain quality (grain length, grain width, amylose content, and gelatinization temperature) using only one MAGIC population. However, for conventional QTL analysis, we have to prepare different bi-parental populations to detect QTLs for different agronomic traits. In terms of efficiency, using MAGIC populations is a cost-effective way to do genetic analysis. Since we also successfully detected many QTLs for 13 kinds of fruit quality traits of cultivated strawberry, the advantages of MAGIC populations discussed in those previous studies were also validated in this study.

\section{Further improvements in genotyping}

In this study, genotyping was conducted with ESTSSR markers that were developed by Isobe et al. (2013). The advantages of SSR markers include the fact that multiple markers can be used in one PCR set and that multi-locus genotyping is possible. However, for the genotyping of a MAGIC population, a marker peak may be derived from more than one locus, and confirming allelic relationships among different peaks is challenging. These complexities make it difficult to map the relevant marker peak to a specific cultivated strawberry sub-genome, and to compare the exact location of QTLs detected in this study with previous studies. In this study, we adapted only GLM (general linear model) to detect QTLs for fruit quality-related traits, and did not use MLM (mixed linear model) methods (Yu et al., 2006) for GWAS. Since GWAS with MLM could detect QTLs while taking into account population structure, it has been thought more useful than that with GLM (Yu et al., 2006). However, we previously demonstrated that our MAGIC population was almost an even mosaic of eight founder parental lines with principle component analysis (Wada et al., 2017), and the population structure did not have to be under consideration for sub- sequent GWAS. Therefore, we adapted only GLM for GWAS in this study.

Bassil et al. (2015) developed a novel genotyping system (i.e., the IStraw90 Axiom ${ }^{\circledR}$ SNP array), and Nagano et al. (2017) performed genotyping of an $S_{1}$ population derived from the self-pollination of a Japanese strawberry cultivar, 'Reikou' with this SNP array. The resulting linkage map included 11,002 SNPs and 572 SSR loci. The marker density was much higher for SNPs than for SSRs, and the locus of each SNP was confirmed. Therefore, applying this array could increase the accuracy of a GWAS in which our MAGIC population is genotyped. Hirakawa et al. (2014) unveiled a draft sequence of the cultivated strawberry genome, and recently Edger et al. (2019) reported its chromosome scale assembly. Combining these genome resources could provide the basis for further GWAS and a GS approach for strawberry.

In conclusion, we herein conducted a GWAS using a MAGIC population derived from six cultivars. This enabled us to detect 166 QTLs, of which most were for fruit firmness. The DNA markers in the vicinity of these QTLs may be useful for accelerating strawberry breeding. Furthermore, fine-mapping of the genes associated with the detected QTLs will be necessary for a comprehensive analysis of QTL functions.

\section{Acknowledgements}

We thank S. Sasamoto, T. Wada, C. Minami, H. Tsuruoka, M. Kato, K. Nannri, and A. Kurabayashi from the Kazusa DNA Research Institute for technical assistance.

\section{Literature Cited}

Bandillo, N., C. Raghavan, P. A. Muyco, M. A. L. Sevilla, I. T. Lobina, C. J. Dilla-Ermita, C.-W. Tung, S. McCouch, M. Thomson and R. Mauleon. 2013. Multi-parent advanced generation inter-cross (MAGIC) populations in rice: progress and potential for genetics research and breeding. Rice 6: 11. DOI: 10.1186/1939-8433-6-11.

Bassil, N. V., T. M. Davis, H. Zhang, S. Ficklin, M. Mittmann, T. Webster, L. Mahoney, D. Wood, E. S. Alperin and U. R. Rosyara. 2015. Development and preliminary evaluation of a $90 \mathrm{~K}$ Axiom $^{\circledR}$ SNP array for the allo-octoploid cultivated strawberry Fragaria $\times$ ananassa. BMC Genomics 16: 155 . DOI: 10.1186/s12864-015-1310-1.

Bringhurst, R. S. 1990. Cytogenetics and evolution in American Fragaria. HortScience 25: 879-881.

Cao, K., Z. Zhou, Q. Wang, J. Guo, P. Zhao, G. Zhu, W. Fang, C. Chen, X. Wang, X. Wang, Z. Tian and L. Wang. 2016. Genome-wide association study of 12 agronomic traits in peach. Nat. Commun. 7: 1-10.

Castro, P. and K. Lewers. 2016. Identification of quantitative trait loci (QTL) for fruit-quality traits and number of weeks of flowering in the cultivated strawberry. Mol. Breed. 36: 138. DOI: 10.1007/s11032-016-0559-7.

Costa, F., C. P. Peace, S. Stella, S. Serra, S. Musacchi, M. Bazzani, S. Sansavini and W. E. Van de Weg. 2010. QTL dynamics for fruit firmness and softening around an ethylenedependent polygalacturonase gene in apple (Malus $\times$ 
domestica Borkh.). J. Exp. Bot. 61: 3029-3039.

da Silva, F. L., M. T. Escribano-Bailón, J. J. P. Alonso, J. C. Rivas-Gonzalo and C. Santos-Buelga. 2007. Anthocyanin pigments in strawberry. LWT-Food Science and Technology 40: 374-382.

Darrow, G. M. 1966. The strawberry. History, breeding and physiology. Holt, Rinehart, and Winston, NewYork.

Edger, P. P., T. J. Poorten, R. VanBuren, M. A. Hardigan, M. Colle, M. R. McKain, R. D. Smith, S. J. Teresi, A. D. L. Nelson, C. M. Wai, E. I. Alger, K. A. Bird, A. E. Yocca, N. Pumplin, S. Ou, G. Ben-Zvi, A. Brodt, K. Baruch, T. Swale, L. Shiue, C. B. Acharya, G. S. Cole, J. P. Mower, K. L. Childs, N. Jiang, E. Lyons, M. Freeling, J. R. Puzey and S. J. Knapp. 2019. Origin and evolution of the octoploid strawberry genome. Nat. Genet. 51: 541-547.

Gezan, S. A., L. F. Osorio, S. Verma and V. M. Whitaker. 2017. An experimental validation of genomic selection in octoploid strawberry. Hortic. Res. 4: 16070.

Hirakawa, H., K. Shirasawa, S. Kosugi, K. Tashiro, S. Nakayama, M. Yamada, M. Kohara, A. Watanabe, Y. Kishida and T. Fujishiro. 2014. Dissection of the octoploid strawberry genome by deep sequencing of the genomes of Fragaria species. DNA Res. 21: 169-181.

Honjo, M., T. Nunome, S. Kataoka, T. Yano, M. Hamano, H. Yamazaki, T. Yamamoto, M. Morishita and S. Yui. 2016. Simple sequence repeat markers linked to the everbearing flowering gene in long-day and day-neutral cultivars of the octoploid cultivated strawberry Fragaria $\times$ ananassa. Euphytica 209: 291-303.

Honjo, M., S. Yui and M. Kunihisa. 2013. Observation of the disomic inheritance of four allelic pairs in the octoploid cultivated strawberry. HortScience 48: 948-954.

Huang, B. E., A. W. George, K. L. Forrest, A. Kilian, M. J. Hayden, M. K. Morell and C. R. Cavanagh. 2012. A multiparent advanced generation inter-cross population for genetic analysis in wheat. Plant Biotechnol. J. 10: 826-839.

Huang, B. E., K. L. Verbyla, A. P. Verbyla, C. Raghavan, V. K. Singh, P. Gaur, H. Leung, R. K. Varshney and C. R. Cavanagh. 2015. MAGIC populations in crops: current status and future prospects. Theor. Appl. Genet. 128: 9991017.

Huang, C., C. Shen, T. Wen, B. Gao, D. Zhu, X. Li, M. M. Ahmed, D. Li and Z. Lin. 2018. SSR-based association mapping of fiber quality in upland cotton using an eight-way MAGIC population. Mol. Genet. Genomics 293: 793-805.

Husaini, A. M. and D. Neri. 2016. Strawberry. Growth, development and diseases. CABI, Wallingford, Oxfordshire, UK.

Isobe, S. N., H. Hirakawa, S. Sato, F. Maeda, M. Ishikawa, T. Mori, Y. Yamamoto, K. Shirasawa, M. Kimura and M. Fukami. 2013. Construction of an integrated high density simple sequence repeat linkage map in cultivated strawberry (Fragaria $\times$ ananassa) and its applicability. DNA Res. 20: 79-92.

Jia, H.-F., Y.-M. Chai, C.-L. Li, D. Lu, J.-J. Luo, L. Qin and Y.-Y. Shen. 2011. Abscisic acid plays an important role in the regulation of strawberry fruit ripening. Plant Physiol. 157: 188199.

Kadomura-Ishikawa, Y., K. Miyawaki, A. Takahashi, T. Masuda and S. Noji. 2015. Light and abscisic acid independently regulated FaMYB10 in Fragaria $\times$ ananassa fruit. Planta 241: 953-965.

Kunihisa, M., N. Fukino and S. Matsumoto. 2005. CAPS markers improved by cluster-specific amplification for identification of octoploid strawberry (Fragaria $\times$ ananassa Duch.) cultivars, and their disomic inheritance. Theor. Appl. Genet. 110:
$1410-1418$.

Kunihisa, M., S. Moriya, K. Abe, K. Okada, T. Haji, T. Hayashi, Y. Kawahara, R. Itoh, T. Itoh and Y. Katayose. 2016. Genomic dissection of a 'Fuji' apple cultivar: re-sequencing, SNP marker development, definition of haplotypes, and QTL detection. Breed. Sci. 66: 499-515.

Lerceteau-Köhler, E., A. Moing, G. Guérin, C. Renaud, A. Petit, C. Rothan and B. Denoyes. 2012. Genetic dissection of fruit quality traits in the octoploid cultivated strawberry highlights the role of homoeo-QTL in their control. Theor. Appl. Genet. 124: 1059-1077.

Lukton, A., C. Chichester and G. Mackinney. 1955. Characterization of a second pigment in strawberries. Nature 176: 790.

Medina-Puche, L., G. Cumplido-Laso, F. Amil-Ruiz, T. Hoffmann, L. Ring, A. Rodríguez-Franco, J. L. Caballero, W. Schwab, J. Muñoz-Blanco and R. Blanco-Portales. 2014. MYB10 plays a major role in the regulation of flavonoid/ phenylpropanoid metabolism during ripening of Fragaria $\times$ ananassa fruits. J. Exp. Bot. 65: 401-417.

Micheletti, D., M. T. Dettori, S. Micali, V. Aramini, I. Pacheco, C. D. S. Linge, S. Foschi, E. Banchi, T. Barreneche and B. Quilot-Turion. 2015. Whole-genome analysis of diversity and SNP-major gene association in peach germplasm. PLOS One 10: e0136803. DOI: 10.1371/journal.pone.0136803.

Monma, S., S. Kamimura and H. Yoshikawa. 1977. Measuring textural characteristics of strawberry fruit using the autograph and push-pull gauge. Bulletin of the Vegetable and Ornamental Crops Research Station. Series D. Morioka.

Nagano, S., K. Shirasawa, H. Hirakawa, F. Maeda, M. Ishikawa and S. N. Isobe. 2017. Discrimination of candidate subgenome-specific loci by linkage map construction with an $\mathrm{S}_{1}$ population of octoploid strawberry (Fragaria $\times$ ananassa). BMC Genomics 18: 374. DOI: 10.1186/s12864017-3762-y.

Ogiwara, I., R. Miyamoto, S. Habutsu, M. Suzuki, N. Hakoda and I. Shimura. 1998. Variation in sugar content in fruit of four strawberry cultivars grown in the field and under forced culture, harvest years, and maturation stages. J. Japan. Soc. Hort. Sci. 67: 400-405.

Pascual, L., N. Desplat, B. E. Huang, A. Desgroux, L. Bruguier, J. P. Bouchet, Q. H. Le, B. Chauchard, P. Verschave and M. Causse. 2015. Potential of a tomato MAGIC population to decipher the genetic control of quantitative traits and detect causal variants in the resequencing era. Plant Biotechnol. J. 13: $565-577$.

Pincot, D. D., T. J. Poorten, M. A. Hardigan, J. M. Harshman, C. B. Acharya, G. S. Cole, T. R. Gordon, M. Stueven, P. P. Edger and S. J. Knapp. 2018. Genome-wide association mapping uncovers Fw1, a dominant gene conferring resistance to Fusarium wilt in strawberry. G3: Genes|Genomes Genetics 8: 1817-1828.

R Core Team. 2016. R: A language and environment for statistical computing. R Foundation for Statistical Computing, Vienna, Austria. $<$ http://www.R-project.org/>.

Rakshit, S., A. Rakshit and J. Patil. 2012. Multiparent intercross populations in analysis of quantitative traits. J. Genet. 91: 111-117.

Rousseau-Gueutin, M., E. Lerceteau-Köhler, L. Barrot, D. J. Sargent, A. Monfort, D. Simpson, P. Arus, G. Guérin and B. Denoyes-Rothan. 2008. Comparative genetic mapping between octoploid and diploid Fragaria species reveals a high level of colinearity between their genomes and the essentially disomic behavior of the cultivated octoploid strawberry. Genetics 179: 2045-2060.

Sargent, D. J., T. Passey, N. Šurbanovski, E. L. Girona, P. Kuchta, 
J. Davik, R. Harrison, A. Passey, A. Whitehouse and D. Simpson. 2012. A microsatellite linkage map for the cultivated strawberry (Fragaria $\times$ ananassa) suggests extensive regions of homozygosity in the genome that may have resulted from breeding and selection. Theor. Appl. Genet. 124: 1229-1240.

Sargent, D. J., Y. Yang, N. Šurbanovski, L. Bianco, M. Buti, R. Velasco, L. Giongo and T. M. Davis. 2016. HaploSNP affinities and linkage map positions illuminate subgenome composition in the octoploid, cultivated strawberry (Fragaria $\times$ ananassa). Plant Sci. 242: 140-150.

Shulaev, V., D. J. Sargent, R. N. Crowhurst, T. C. Mockler, O. Folkerts, A. L. Delcher, P. Jaiswal, K. Mockaitis, A. Liston and S. P. Mane. 2011. The genome of woodland strawberry (Fragaria vesca). Nat. Genet. 43: 109. DOI: 10.1038/ ng. 740 .

Sone, K., T. Mochizuki and Y. Noguchi. 2002. Varietal differences and heritability of sugar and organic acid contents and composition in strawberry fruit. Bull Natal Res Inst Veg, Ornam Plants \& Tea Japan 1: 241-254.

Sugimoto, T., K. Tamaki, J. Matsumoto, Y. Yamamoto, K. Shiwaku and K. Watanabe. 2005. Detection of RAPD markers linked to the everbearing gene in Japanese cultivated strawberry. Plant Breed. 124: 498-501.

Tennessen, J. A., R. Govindarajulu, T.-L. Ashman and A. Liston. 2014. Evolutionary origins and dynamics of octoploid strawberry subgenomes revealed by dense targeted capture linkage maps. Genome Biol. Evol. 6: 3295-3313.

Urrestarazu, J., H. Muranty, C. Denancé, D. Leforestier, E. Ravon, A. Guyader, R. Guisnel, L. Feugey, S. Aubourg and J.-M. Celton. 2017. Genome-wide association mapping of flowering and ripening periods in apple. Front. Plant Sci. 8: 1923. DOI: 10.3389/fpls.2017.01923.

Verma, S., J. D. Zurn, N. Salinas, M. M. Mathey, B. Denoyes,
J. F. Hancock, C. E. Finn, N. V. Bassil and V. M. Whitaker. 2017. Clarifying sub-genomic positions of QTLs for flowering habit and fruit quality in U.S. strawberry (Fragaria $\times$ ananassa) breeding populations using pedigree-based QTL analysis. Hortic. Res. 4: 17062. DOI: 10.1038/hortres.2017. 62.

Wada, T., K. Oku, S. Nagano, S. Isobe, H. Suzuki, M. Mori, K. Takata, C. Hirata, K. Shimomura and M. Tsubone. 2017. Development and characterization of a strawberry MAGIC population derived from crosses with six strawberry cultivars. Breed. Sci. 67: 370-381.

Weebadde, C., D. Wang, C. Finn, K. Lewers, J. J. Luby, J. Bushakra, T. Sjulin and J. Hancock. 2008. Using a linkage mapping approach to identify QTL for day-neutrality in the octoploid strawberry. Plant Breed. 127: 94-101.

Yoshida, Y. and H. Tamura. 2005. Variation in concentration and composition of anthocyanins among strawberry cultivars. J. Japan. Soc. Hort. Sci. 74: 36-41.

Yoshida, Y., N. Koyama and H. Tamura. 2002. Color and anthocyanin composition of strawberry fruit: Changes during fruit development and differences among cultivars, with special reference to the occurrence of pelargonidin 3malonylglucoside. J. Japan. Soc. Hort. Sci. 71: 355-361.

Yu, J., G. Pressoir, W. H. Briggs, I. V. Bi, M. Yamasaki, J. F. Doebley, M. D. McMullen, B. S. Gaut, D. M. Nielsen and J. B. Holland. 2006. A unified mixed-model method for association mapping that accounts for multiple levels of relatedness. Nat. Genet. 38: 203-208.

Zorrilla-Fontanesi, Y., A. Cabeza, P. Domínguez, J. J. Medina, V. Valpuesta, B. Denoyes-Rothan, J. F. Sánchez-Sevilla and I. Amaya. 2011. Quantitative trait loci and underlying candidate genes controlling agronomical and fruit quality traits in octoploid strawberry (Fragaria $\times$ ananassa). Theor. Appl. Genet. 123: 755-778. 